\title{
Influence of Wheel Eccentricity on Vertical Vibration of Suspended Monorail Vehicle: Experiment and Simulation
}

\author{
Kaikai Lv, Kaiyun Wang, Zhihui Chen, Chengbiao Cai, and Lirong Guo \\ State Key Laboratory of Traction Power, Southwest Jiaotong University, Chengdu 610031, China \\ Correspondence should be addressed to Kaiyun Wang; kywang@swjtu.edu.cn
}

Received 28 July 2017; Revised 8 November 2017; Accepted 3 December 2017; Published 20 December 2017

Academic Editor: Abdul Qadir Bhatti

Copyright (c) 2017 Kaikai Lv et al. This is an open access article distributed under the Creative Commons Attribution License, which permits unrestricted use, distribution, and reproduction in any medium, provided the original work is properly cited.

\begin{abstract}
This paper investigates the influence of wheel eccentricity on vertical vibration of suspended monorail vehicle based on experiment and simulation. Two sets of tests are conducted in the first Chinese suspended monorail, and the tested acceleration is analyzed and exhibited. A multibody dynamic model of the suspended monorail vehicle is established to simulate the vertical vibration of car body excited by wheel eccentricity. The results show that there are three factors which may cause an abnormal vibration considering the track and the vehicle system. The influence of wheel eccentricity on the car body vibration was firstly analyzed. Simulated acceleration of car body has a great accordance with test. The wheel eccentricity could excite the resonance of car body at the speed of $21 \mathrm{~km} / \mathrm{h}$, and the vertical acceleration would increase considerably. Decreasing the secondary stiffness can effectively reduce the vertical vibration caused by wheel eccentricity, especially at the resonant speed. In the secondary test, the peak of car body acceleration at speed of $20 \mathrm{~km} / \mathrm{h}$ is not appearing when only renewing the wheels, and the acceleration is decreasing obviously at the domain frequency. It is further determined that the abnormal vibration is mainly caused by the wheel eccentricity.
\end{abstract}

\section{Introduction}

Nowadays, most Chinese cities are facing the pressure of traffic jam. As to solve the problem, a large number of shortdistance transportation systems are built, such as subways, light rail transit, bus rapid transit (BRT), maglev transit, and straddle monorail [1]. And now, another new transportation is developed, suspended monorail. This new form of transportation is researched and developed, and the experimental stage has been finished. Several problems of vehicle and monorail track were found and solved at the experimental stage, such as the wheel eccentricity.

Wheel eccentricity is mainly caused by misalignment in the fixation of the wheel during manufacturing or maintenance and is a special classification of wheel out-of-roundness (OOR) [2]. The wheel OOR is a common phenomenon in railway vehicles, which could cause high-frequency forces between wheel and rail with the increasing of the running speed [3-5]. In addition, under the certain periodic excitation, the running comfort of the vehicle is severely threatened $[6,7]$. A number of scholars have been devoted to investigate the mechanism and the influence of wheel OOR in railway. Jin et al. [8] investigated the mechanism of the polygonal wear of metro train wheels based on experiment and structure model test, and the average passing frequency of a polygonal wheel is approximately close to the first bending resonant frequency of the wheelset, which is the main reason of the polygonal wear. More than 2000 wheels of seven types of locomotives widely used in China have been measured [9], two types of fright traffic locomotives suffer serious polygonal wear problem, and the other types exhibited more or less wheel eccentricity. Johansson and Andersson [10,11] analyzed and summarized the extensive wheel measurement campaign performed in Sweden, the wheel roughness and the rail roughness were also been compared, and a tool was developed for investigation of wheel tread polygonal wear. The mechanism of the wheel OOR was explained by a simple model proposed by Brommundt [12]. Badger et al. [13] studied the evident degradation of the grinding force, wheel wear, and vibration caused by the wheel eccentricity, and some recommendations are given for detecting and determining the wheel eccentricity. Wu et al. [14] studied the dynamic stresses of the wheel set 


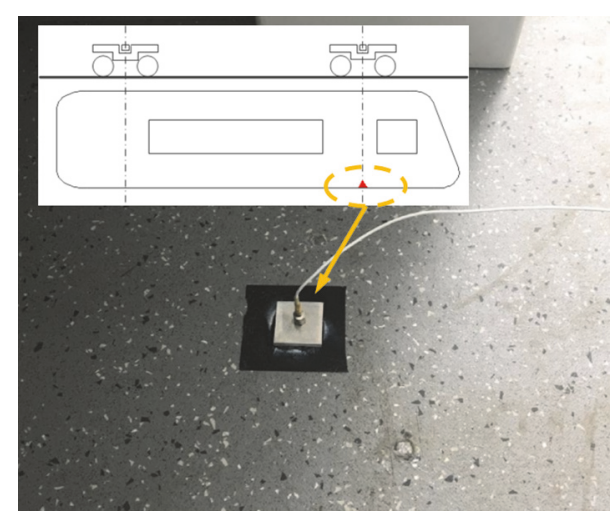

(a)

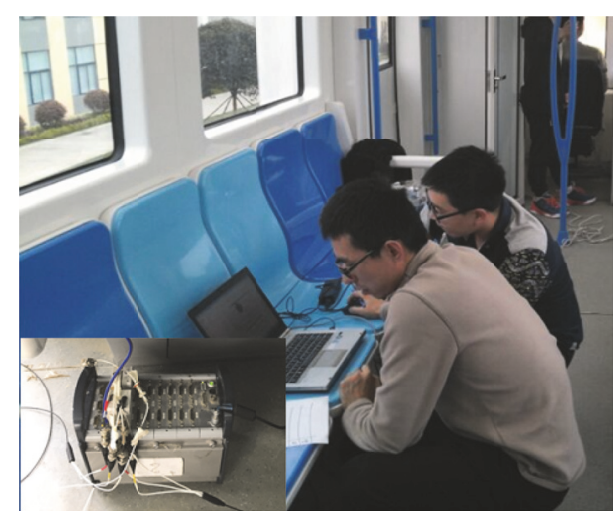

(b)

FIGURE 1: Acceleration measurement of the car body: (a) sensor position and (b) data acquisition.

axle based on a coupled vehicle/track dynamic model with the flexible wheelset; the results show that the resonance of wheel set axle could be excited by polygonal wear, which would increase the dynamic stress for the wheel set axle. The growth mechanism of wheel polygonal of railway vehicle and its damage for the track and components were overviewed in detail $[2,15,16]$. Although a great number of researches have been carried out by scholars all over the world, the OOR of the railway wheels has not been completely explained and solved [14].

For the first suspended monorail vehicle in China, an abnormal vertical vibration of car body was found in the experimental stage, which seriously affects the ride comfort. The objective of this paper is to validate the wheel eccentricity which is the root cause for this abnormal vibration of car body based on experiment and simulation. And the influence mechanism of the wheel eccentricity on the car body acceleration is also analyzed.

\section{Investigation on the Vertical Vibration of Car Body by First Test}

On the trial running stage of the first suspended monorail vehicle in China, the vertical vibration of the car body exhibited an abnormal phenomenon. The obvious feature of the vibration is that it shows a clear resonance characteristic, and the amplitude of vibration was particularly violent at the speed of about $20 \mathrm{~km} / \mathrm{h}$. The ride comfort is extremely influenced by the abnormal vibration, and the maximum speed of the vehicle is therefore limited. As to explore the root reason of this special vibration, the first test was conducted.

2.1. Description of the First Test. The test was conducted in the first suspended monorail line of China, aiming to find the main reason of the abnormal vibration. This test mainly measured the vertical acceleration of the car body, the acceleration sensors was mounted on the floor of car body, as shown in Figure 1(a), and Figure 1(b) shows the data acquisition.

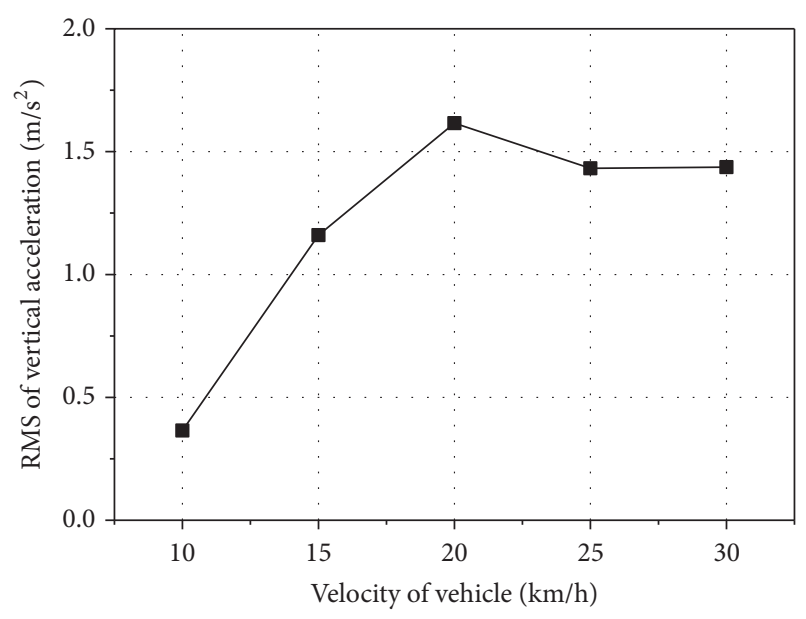

FIGURE 2: Measured acceleration of car body at different velocity.

In this test, the velocity of the vehicle was set to 10 $30 \mathrm{~km} / \mathrm{h}$ and the interval was $5 \mathrm{~km} / \mathrm{h}$. Due to the fact that the cause of the abnormal vibration is not clear, the maximum speed of $30 \mathrm{~km} / \mathrm{h}$ was mainly to ensure the running safety.

2.2. Results and Discussion of the First Test. Analyzing the measured data was the key means to find the cause of vibration. Firstly, the RMS of the acceleration was counted to represent the level of the vertical vibration, and its variation trend with speeds is illustrated in Figure 2. It can be seen that, at the speed of $20 \mathrm{~km} / \mathrm{h}$, the maximum amplitude of the acceleration for the car body increases considerably and reaches a peak of $1.62 \mathrm{~m} / \mathrm{s}^{2}$. The test results show a very uniformity with the travel experience.

In order to further analyze the measured data, the frequency spectrum of the measured acceleration is shown in Figure 3. It can be clearly found that each acceleration has a certain domain frequency. With the increase of running speed, the domain frequency increased accordingly. 


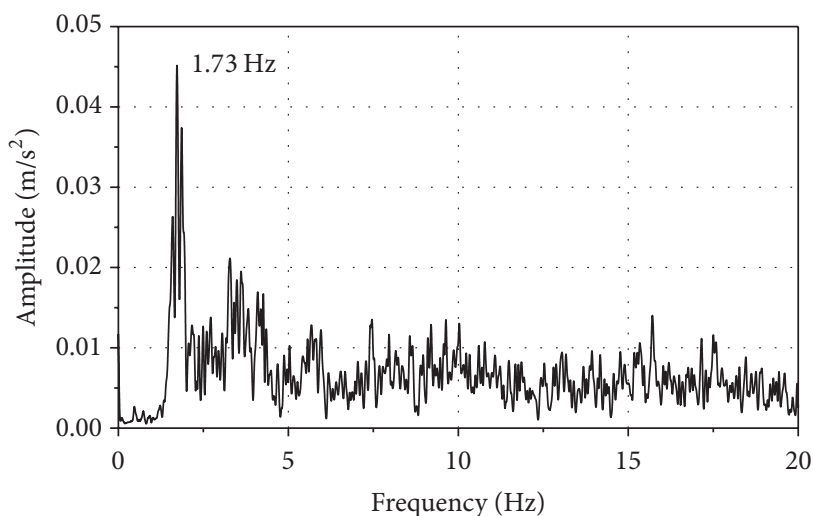

(a)

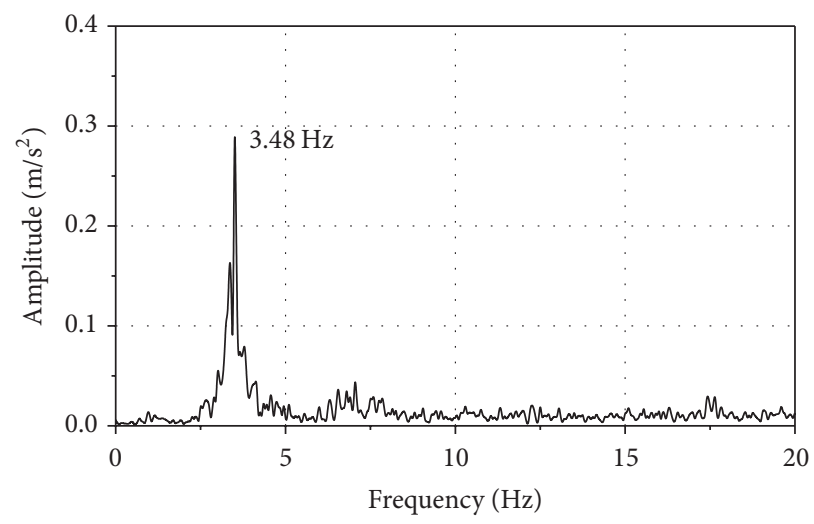

(c)

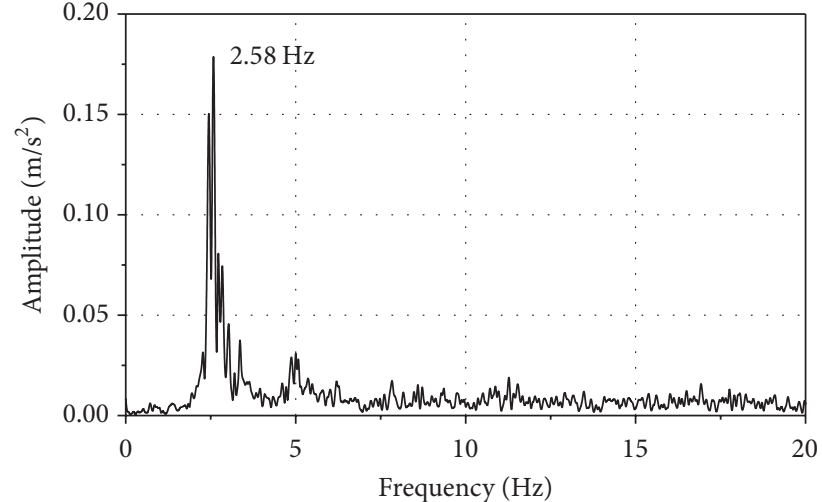

(b)

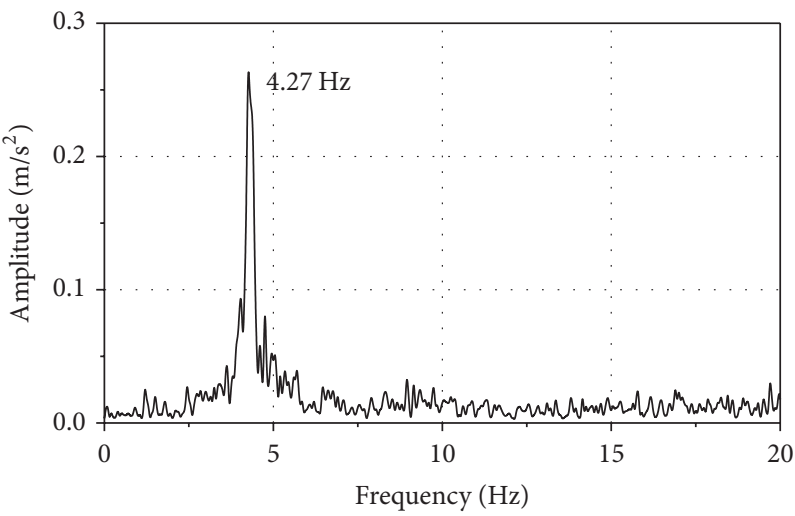

(d)

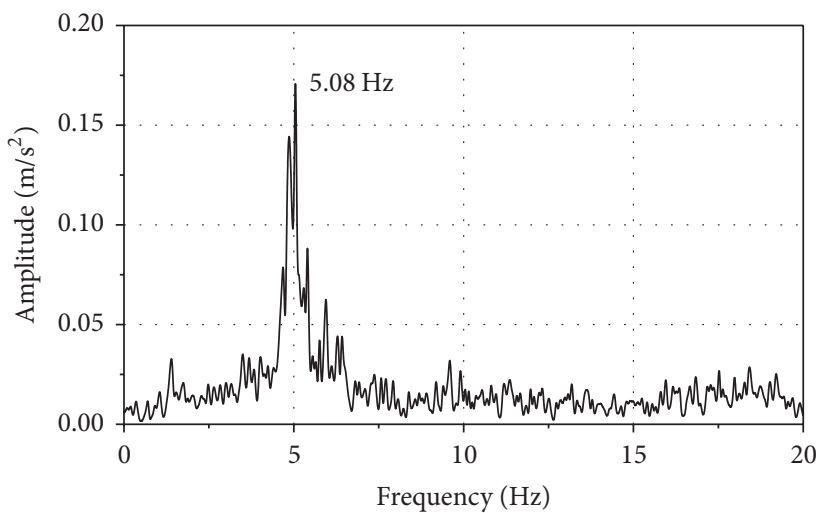

(e)

Figure 3: The frequency spectrum of the measured acceleration at different speeds: (a) $10 \mathrm{~km} / \mathrm{h}$, (b) $15 \mathrm{~km} / \mathrm{h},(\mathrm{c}) 20 \mathrm{~km} / \mathrm{h}$, (d) $25 \mathrm{~km} / \mathrm{h}$, and (e) $30 \mathrm{~km} / \mathrm{h}$.

It is known that vibration is caused by the excitation, and excitation is mainly generated from the vehicle itself and the track. The relationship among domain frequency of measured acceleration, wavelength of the excitation, and the velocity is as follows:

$$
\lambda=\frac{v}{f}
$$

where $\lambda$ denotes the wavelength of excitation, $v$ is the running velocity, and $f$ is the domain frequency of vibration.
TABLE 1: Calculated wavelength of excitation.

\begin{tabular}{lccccc}
\hline Velocity $(\mathrm{km} / \mathrm{h})$ & 10 & 15 & 20 & 25 & 30 \\
\hline Domain frequency $(\mathrm{Hz})$ & 1.73 & 2.58 & 3.48 & 4.27 & 5.08 \\
Calculated wavelength $(\mathrm{m})$ & 1.61 & 1.61 & 1.60 & 1.63 & 1.64 \\
\hline
\end{tabular}

According to formula (1), the excited wavelength at each speed can be calculated, as listed in Table 1 . 


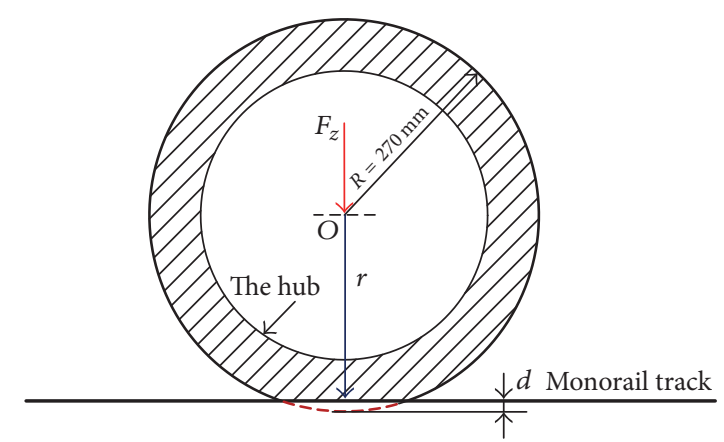

FIGURE 4: Schematic diagram of compressed wheel.

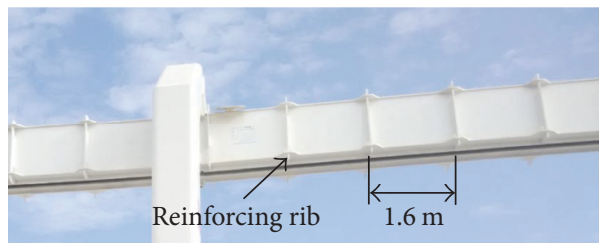

(a)

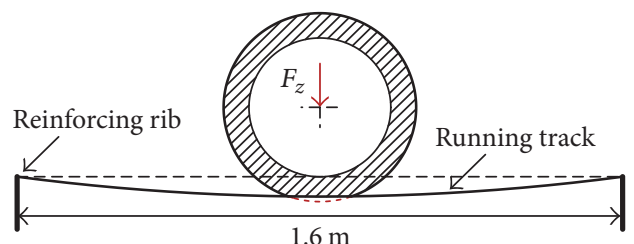

(b)

FIGURE 5: The monorail track: (a) the reinforcing rib and (b) the compressed deformation of track.

The calculated wavelengths in Table 1 are $1.60 \sim 1.64 \mathrm{~m}$, which can conclude that the main wavelength of the excitation is $1.60 \sim 1.64 \mathrm{~m}$, and this is the main reason for the abnormal vibration.

2.3. The Possibilities for the Excitation. According to the measured car body acceleration, the existence of the excitation with 1.6 1.64 m wavelength is the cause for abnormal vibration. For this type of excitation, there have three possibilities considering the track and vehicle system.

(1) The Wheel Eccentricity. The radius of the wheel is $0.27 \mathrm{~m}$, and the wheel circumference is $1.70 \mathrm{~m}$. But it is noted that the wheel of suspended monorail vehicle is solid tire and the compressed deformation cannot be ignored during running, as shown in Figure 4. The axle load of the vehicle is $4 t$, the static vertical force $F_{z}$ is about $20 \mathrm{kN}$, and the compressed deformation $d$ is about $6.7 \mathrm{~mm}$. In this condition, the rolling radius $r$ decreased to $0.263 \mathrm{~m}$, the rolling circumference decreased to about $1.65 \mathrm{~m}$, and this is in great accordance with the domain wavelength of the excitation.

(2) The Inherent Characteristics of the Monorail Track. Figure 5(a) shows the monorail track, and in order to ensure the running safe, the reinforcing rib is used to promote the reliability of the running track. When the vehicle passes, the unevenness of the track stiffness will cause the vibration $[17,18]$, as shown in Figure 5(b). The designed interval of the rib is $1.6 \mathrm{~m}$, which is also in great accordance with the domain wavelength of the excitation.

(3) The Track Irregularity. If the wavelength of irregularity is concentrated at about $1.6 \mathrm{~m}$, the excited vibration of car body will show the measured characteristic.
As the above analysis, there are three factors which may cause the abnormal vibration considering the track and the vehicle system. To improve the ride comfort, the effective strategy for the three factors is introduced. For the reinforcing rib, it is the inherent characteristic of the track to ensure running safety. The influence of rib on the car body vibration is inevitable but could effectively reduce by matching the vehicle parameters. As to the track irregularity, grinding the track surface could smooth the track and improve the ride comfort. In general, the irregularity is random, so the abnormal vibration is not likely caused by the irregularity. For wheel eccentricity, controlling the errors of manufacture and installation could reduce its influence on the ride comfort significantly.

Modifying the reinforcing rib and track irregularity is difficult operation, especially on the line that has been built. But the detection and elimination of wheel eccentricity are easy. So, the influence of the wheel eccentricity on the vertical vibration of the car body is firstly analyzed.

\section{Multibody Dynamic Simulation}

In this section, numerical simulations are conducted to give an insight into the consequent influence of the wheel eccentricity on the vehicle vibration. Only the wheel eccentricity is considered in the simulation. The results are compared with the test date, which can provide the evidence for the causes of the abnormal vibration.

3.1. Dynamic Model of Suspended Monorail Vehicle. In order to analyze the influence of the wheel eccentricity on the car body vibration, a detailed simulation model has been established using the multibody dynamic software of SIMPACK, as 


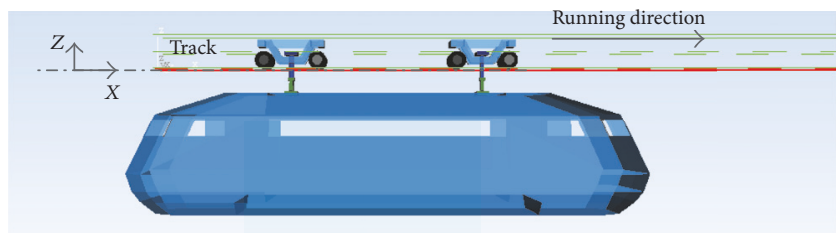

FIGURE 6: The simulation models for suspended monorail vehicle.

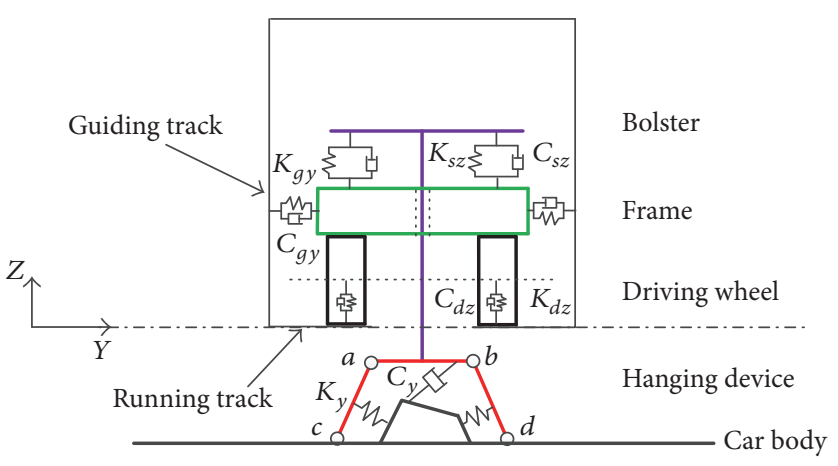

Figure 7: The simulation models of bogie.

illustrated in Figure 6. In this model, the vehicle was treated as a full rigid multibody dynamic model, and the flexibility of the monorail track is not considered. The monorail track is box-sectioned beams with bottom opening, as shown in Figure 5(a). The bogie is placed inside the box beams, which could avoid the influence of the weather. The car body is suspended under the bogie; thus it can be running in the sky.

The suspended monorail vehicle consists of two bogies, and each bogie is mainly made up of one frame, one bolster, four driving wheels, four guiding wheels, a hanging device, and suspension systems. The structure of the bogie can be clearly seen in Figure 7.

The driving wheel (solid rubber tire) is running on the running track, acting as the primary suspension. Each driving wheel can be rotated around the bogie, independently. In the dynamic model, the tire model of Pacejka Magic Formula was referenced to calculate the interaction between the driving wheel and the track, and $C_{d z}$ and $K_{d z}$ are representing the vertical damping and stiffness of the driving tire.

Not like the self-steering performance of the railway vehicle, the guiding wheels are needed to provide the steering force when the suspended monorail vehicle passes curve. The guiding wheels are also solid rubber tire, and they are running along the guiding track. In order to ensure the curving passing performance of the vehicle, the guiding wheels have an initial compression to provide an initial lateral force. In the dynamic model, the linear force element was used to simulate the guiding force, and $C_{g y}$ and $K_{g y}$ are representing the damping and stiffness of the guiding wheel.

The connection between the car body and the bolster is the hanging device, and the points $a, b, c$, and $d$ are four rotated joints, which can rotate around the $x$-axis. There has one damper between the car body and the hanging device, which is used to reduce the lateral vibration of the car body, and $C_{y}$ represents its damping. The lateral stopper between car body and hanging device limits the large lateral rotation angle of the car body, and $K_{y}$ represents the stiffness of the stopper.

Two sets of spring-damper systems are installed between the bolster and the frame, where $C_{s z}$ and $K_{s z}$ are representing the damping and stiffness.

3.2. Eccentricity Model of Monorail Wheel. The wheel OOR is a very common phenomenon in the railway vehicle, and a lot of investigations have been done aiming at this uneven problem. As to the wheel OOR model, two main methods are used to describe the polygonal wear in the wear circumferential direction in railway, as shown in Figure 8.

The first method is transforming the wheel OOR into the track irregularity, and the wheel surface is kept constant. The second method is using the harmonic deviation of the wheel radius to describe the wheel OOR. The formulas of the harmonic deviation are given as follows [19]:

$$
\begin{aligned}
\Delta r & =A \cdot \sin (n \cdot \theta) \\
r & =R-\Delta r,
\end{aligned}
$$

where $A$ denotes the amplitude of the polygonal wear, $R$ is the radius of the wheel, $n$ is the order of polygon wear, $\theta$ is the wheel rotation angle, and $r$ is the actual radius of the wheel from the central axis, which is related to $\theta$.

In the monorail vehicle, the compressed deformation of tire cannot be ignored which is caused by vertical forces. Therefore, the second method was chosen to investigate the influence of the wheel eccentricity on the vertical vibration of monorail vehicle. 


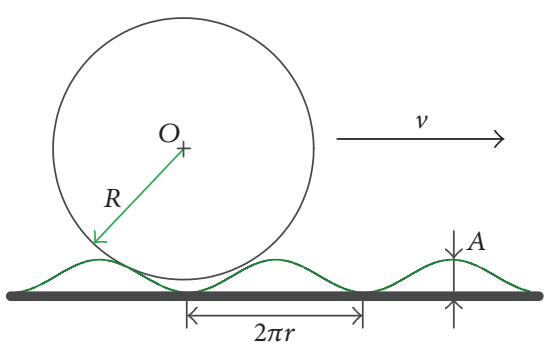

(a)

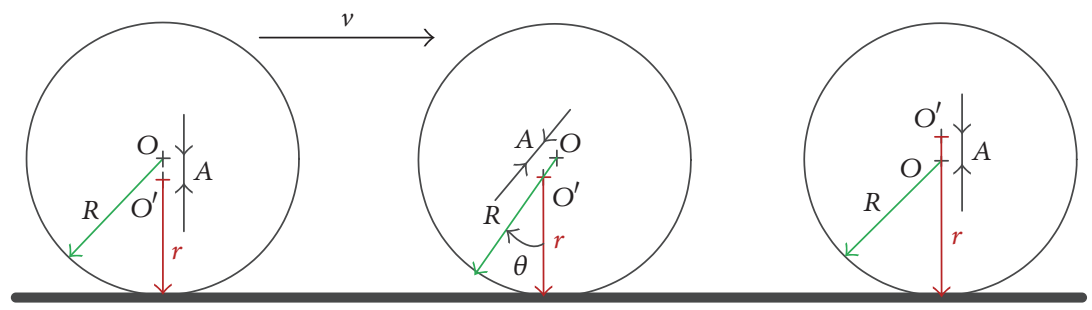

(b)

FIGURE 8: Methods to describe the wheel OOR: (a) transforming into track irregularity and (b) the harmonic deviation.

TABLE 2: Main parameters of the vehicle.

\begin{tabular}{lcc}
\hline Parameters & Value & Units \\
\hline Axle load & 4000 & $\mathrm{~kg}$ \\
Bogie distance & 5900 & $\mathrm{~mm}$ \\
Driving wheel base & 1500 & $\mathrm{~mm}$ \\
Guiding wheel base & 2900 & $\mathrm{~mm}$ \\
Driving wheel radius & 270 & $\mathrm{~mm}$ \\
Mass of car body & 7500 & $\mathrm{~kg}$ \\
Mass of bogie & 1000 & $\mathrm{~kg}$ \\
Vertical stiffness of driving wheel & 3.0 & $\mathrm{MN} / \mathrm{m}$ \\
Vertical stiffness of guiding wheel & 1.8 & $\mathrm{MN} / \mathrm{m}$ \\
Secondary stiffness $z$-axis (one side) & 1.0 & $\mathrm{MN} / \mathrm{m}$ \\
Secondary damper $z$-axis (one side) & 30 & $\mathrm{kN} \cdot \mathrm{s} / \mathrm{m}$ \\
lateral damper $\left(C_{y}\right.$ ) & 30 & $\mathrm{kN} \cdot \mathrm{s} / \mathrm{m}$ \\
\hline
\end{tabular}

3.3. Dynamic Vibration of Car Body with Wheel Eccentricity at Different Speeds. In the simulation, only the excitation of wheel eccentricity is considered. All the driving wheels are equipped with wheel eccentricity and no phase difference exists. The vehicle was running on the tangent track. The main parameters of the suspended monorail vehicle used in the simulation are listed in Table 2.

The effects of the wheel eccentricity and its amplitude on the vertical acceleration of car body are illustrated in Figure 9. It can be observed that, with the increase of the eccentricity amplitude, the vertical acceleration of car body is increasing correspondingly. But the variation trend of the vertical acceleration of car body with the speed is not influenced by the amplitude of the wheel eccentricity. In the speed range $(v<21 \mathrm{~km} / \mathrm{h})$, the acceleration of car body is obviously increased with the speed rising. Nevertheless, when the speed is in the range of $21 \mathrm{~km} / \mathrm{h}<v<35 \mathrm{~km} / \mathrm{h}$, the car body acceleration decreases gradually. With the continuous increasing in the velocity, the acceleration of car body induced by the wheel eccentricity rises gradually. There is a peak at the speed of $21 \mathrm{~km} / \mathrm{h}$, which means that the vertical vibration of the car body is more obvious, and this is fully coincided with the experiment.

To understand the effects of the wheel eccentricity on the vibration of the car body, the time history of the vertical acceleration of the car body at the speed of $21 \mathrm{~km} / \mathrm{h}$ is shown in Figure 10. The amplitude of wheel eccentricity is set to

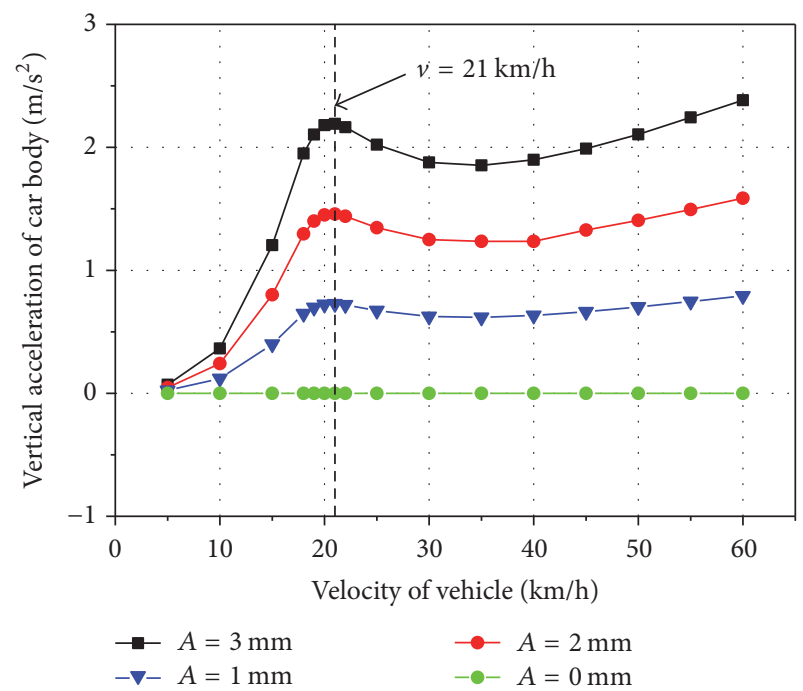

FIGURE 9: Vertical acceleration of car body at different speeds.

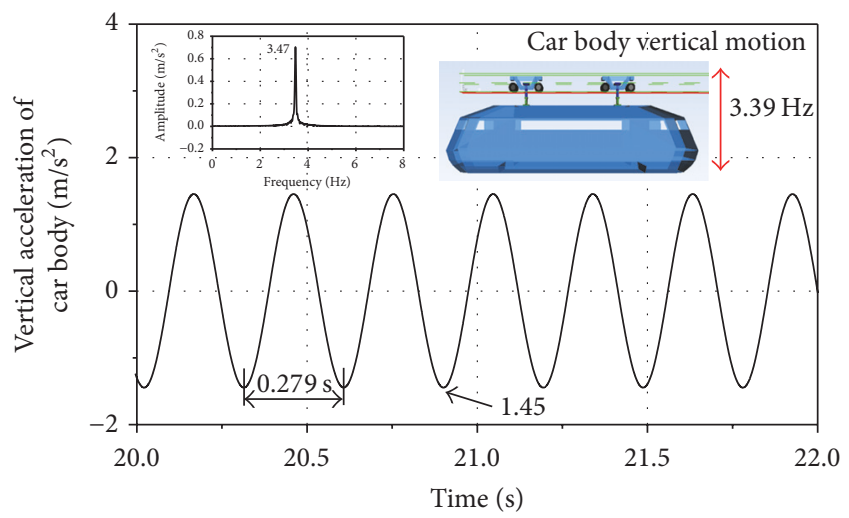

FIGURE 10: Vertical acceleration of car body at the speed of $21 \mathrm{~km} / \mathrm{h}$.

$2 \mathrm{~mm}$. For the case of wheel with eccentricity, the maximum vertical acceleration of car body is about $1.45 \mathrm{~m} / \mathrm{s}^{2}$. The period of the oscillation of the acceleration is about $0.279 \mathrm{~s}$. According to the calculated results, the excitation frequency of wheel eccentricity for the car body acceleration at the speed of $21 \mathrm{~km} / \mathrm{h}$ is $3.47 \mathrm{~Hz}$ approximately, which gets close to the resonant frequency of the car body vertical motion $3.39 \mathrm{~Hz}$. Therefore, the wheel eccentricity attributes to the vertical 


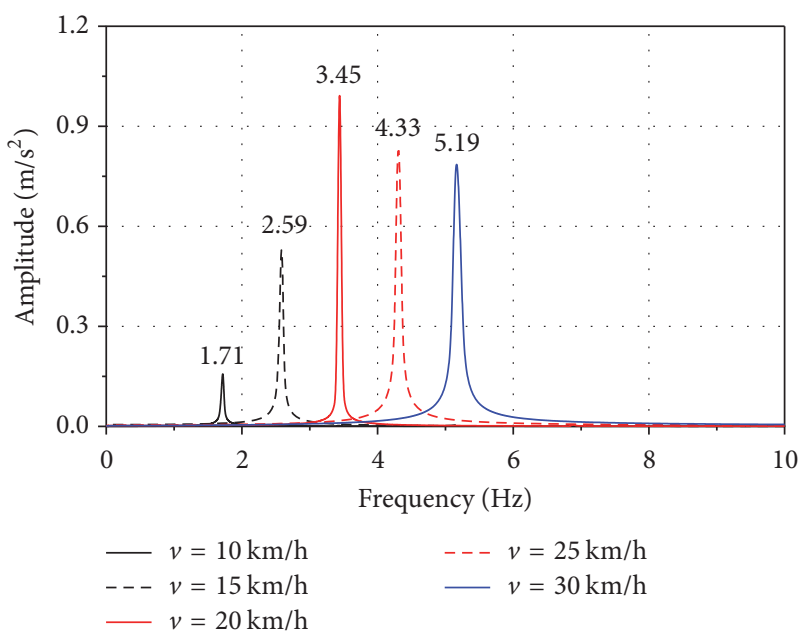

FIGURE 11: The frequency spectrum of the simulated acceleration at different speeds.

TABLE 3: Simulated dominant frequency of car body acceleration.

\begin{tabular}{lccccc}
\hline Velocity $/(\mathrm{km} / \mathrm{h})$ & 10 & 15 & 20 & 25 & 30 \\
\hline Simulated $/ \mathrm{Hz}$ & 1.71 & 2.59 & 3.45 & 4.33 & 5.19 \\
Experiment $/ \mathrm{Hz}$ & 1.73 & 2.58 & 3.48 & 4.27 & 5.08 \\
\hline
\end{tabular}

resonance of car body at the speed of $21 \mathrm{~km} / \mathrm{h}$, so that the vertical vibration of car body is rising considerably.

Figure 11 shows the frequency spectrum of the vertical acceleration of car body at different speeds. It can be seen that there is a major frequency existing in the frequency domain, which is induced by the wheel eccentricity.

The comparison of simulated and experiment results in the dominant frequency of the car body acceleration which is showed in Table 3. It can be clear seen that the calculated domain frequency of car body acceleration with wheel eccentricity shows well accordance with the experiment. This comparison further verifies that the wheel eccentricity may cause the abnormal vibration of car body.

3.4. Influence of the Secondary Suspension on the Vibration of Car Body with Wheel Eccentricity. The vibration induced by wheel eccentricity transfers to the car body, which will seriously affect the ride comfort. For the suspended monorail vehicle, the secondary suspension is the most important component to attenuate the car body vibration, so its effect on the car body acceleration is calculated in the excitation of wheel eccentricity, which is hoped to reduce the influence of wheel eccentricity on ride comfort. The cases of vertical acceleration of car body with different secondary stiffness and damping are compared, as shown in Figure 12. The amplitude of wheel eccentricity is also set to $2 \mathrm{~mm}$ in the simulation.

Figure 12(a) indicates that, with the decrease of the secondary stiffness, the vertical acceleration of car body decrease significantly. When the stiffness decreased to $0.3 \mathrm{MN} / \mathrm{m}$, the abnormal vibration is not appearing at low speed $(<20 \mathrm{~km} / \mathrm{h})$. When the stiffness increased to $1.5 \mathrm{MN} / \mathrm{m}$, the peak of vertical acceleration is appearing at the speed of $23 \mathrm{~km} / \mathrm{h}$, which is a little higher than the stiffness of $1.0 \mathrm{MN} / \mathrm{m}$.

The comparison analysis for the effect of the secondary damping on the vertical acceleration of car body with wheel eccentricity is demonstrated in Figure 12(b). When the speed is lower than $25 \mathrm{~km} / \mathrm{h}$, increasing the secondary damping can effectively reduce the car body acceleration caused by the wheel eccentricity. However, when the speed is higher than $25 \mathrm{~km} / \mathrm{h}$, the index of car body acceleration is rising with the increasing of the secondary damping.

\section{Investigation on the Vertical Vibration of Car Body by Second Test}

From the above analysis, the calculated result with wheel eccentricity shows a great accordance with the experiment. But the reinforcing rib and the track irregularity were not considered in the simulation. In order to verify that the abnormal vibration was induced by the wheel eccentricity, the secondary test is conducted. New wheel without eccentricity was installed on the vehicle and the monorail track was as same as the first test, so as the sensor position and test methods.

Figure 13 gives the comparison of the two test results of car body vertical acceleration. It should be noted that the maximum speed in the second test is set to $60 \mathrm{~km} / \mathrm{h}$.

It can be observed that the overall trend of the vertical acceleration of the car body increases as the vehicle velocity rising in the second test. Compared to the first test, the peak of car body acceleration at speed of $20 \mathrm{~km} / \mathrm{h}$ is not appearing, which states that the vertical resonance of car body disappeared when renewing the wheel without eccentricity.

Figure 14 gives the comparison of the frequency spectrum of the two test results at different speeds. In the case of the second test, the car body acceleration is decreasing obviously at the domain frequency. Therefore, it can be deduced that the main reason of the abnormal vibration in the first test is wheel eccentricity.

From the comparison of the two tests, the abnormal vertical vibration of car body was disappearing when only eliminate the wheel eccentricity. Because the track is the same in the two tests, it could confirm that the wheel eccentricity is the main reason of the abnormal vibration. Meanwhile, the domain frequency also can be seen at low frequency, this may mainly cause the irregularity and the reinforcing rib existing on the monorail track, and its influence and optimization will be carried out in the future work.

\section{Conclusions}

In this study, the influence of the wheel eccentricity on the vertical vibration of suspension monorail vehicle is investigated and validated, based on extensive experiments and simulation. The main conclusions can be drawn as follows:

(1) Based on the amplitude-frequency characteristic of the vertical acceleration in the first test, three possible reasons are proposed, which may cause the abnormal vibration of car body. 


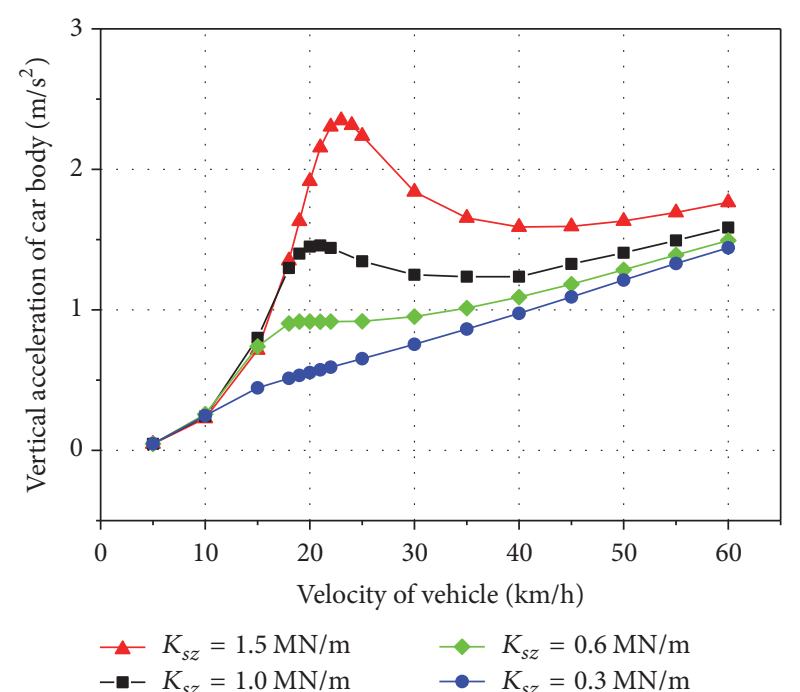

(a)

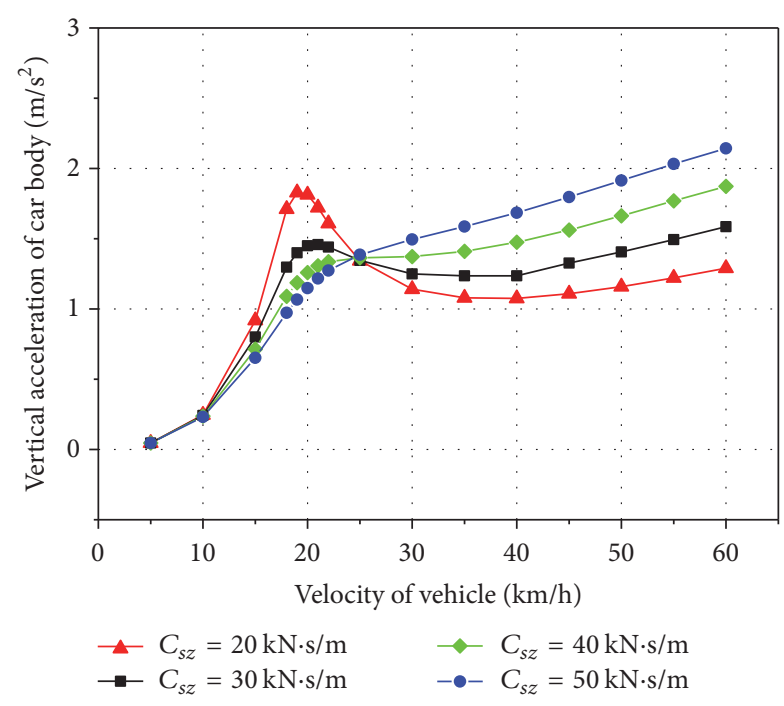

(b)

FIGURE 12: The effect of secondary suspension on the vibration of car body with wheel eccentricity: (a) stiffness and (b) damping.

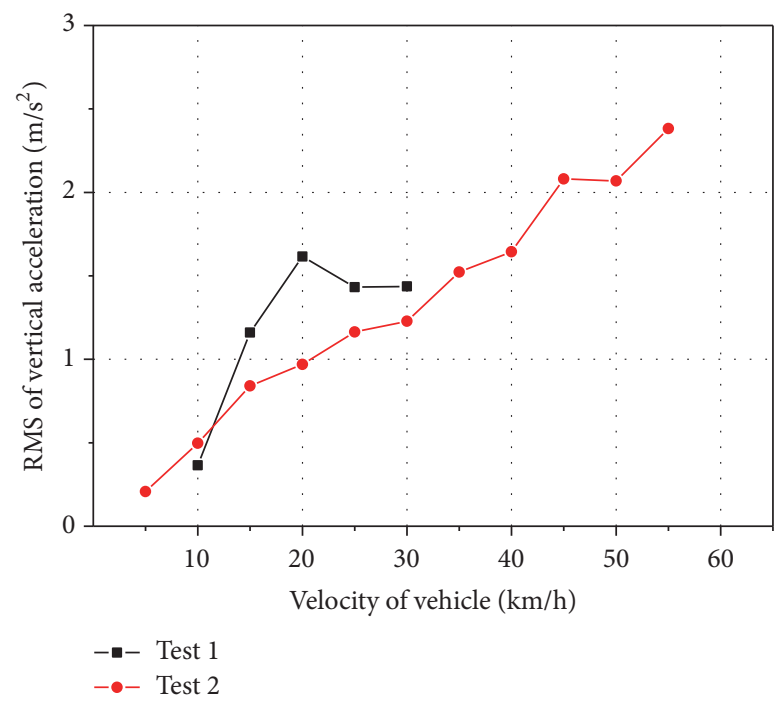

Figure 13: The comparison of the two test results.

(2) The simulated acceleration excited only by wheel eccentricity shows great accordance with the first tested results. The variation trend of the acceleration is not influenced by the amplitude of wheel eccentricity. The vertical vibration induced by the wheel eccentricity could excite the resonance of car body at the speed of $21 \mathrm{~km} / \mathrm{h}$.

(3) Decreasing the secondary stiffness can significantly reduce the vertical vibration of the car body caused by wheel eccentricity, especially at the resonant speed. As to the secondary damping, increasing the secondary damping can effectively reduce the car body acceleration caused by the wheel eccentricity at low speed
$(<25 \mathrm{~km} / \mathrm{h})$. However, the index of car body acceleration is rising with the increasing of the secondary damping as the speed is higher.

(4) In the case of the second test with new wheel, the peak of car body acceleration at speed of $21 \mathrm{~km} / \mathrm{h}$ is not appearing, and the car body acceleration is decreasing obviously at the domain frequency. It is further determined that the abnormal vibration is mainly caused by the wheel eccentricity.

It should be noted that the flexibility of the monorail track is not considered in this study. However, in the real condition the track is not rigid; thus, it is necessary to take 


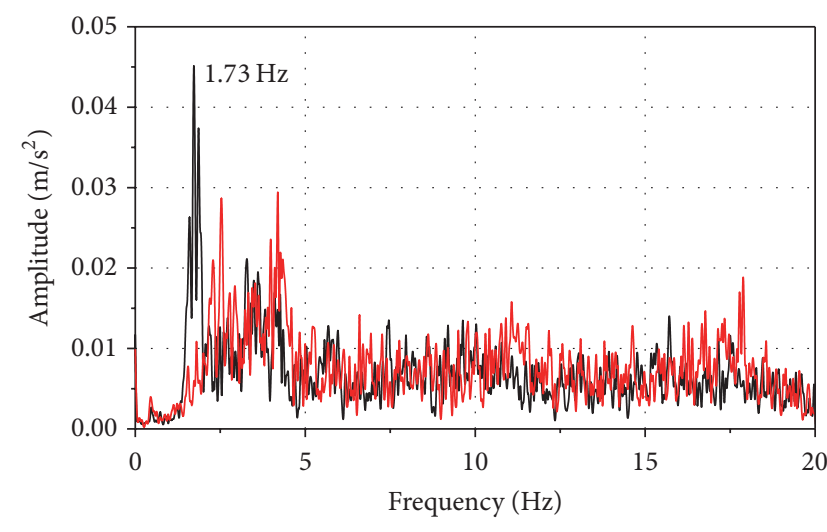

Test 1
— Test 2

(a)

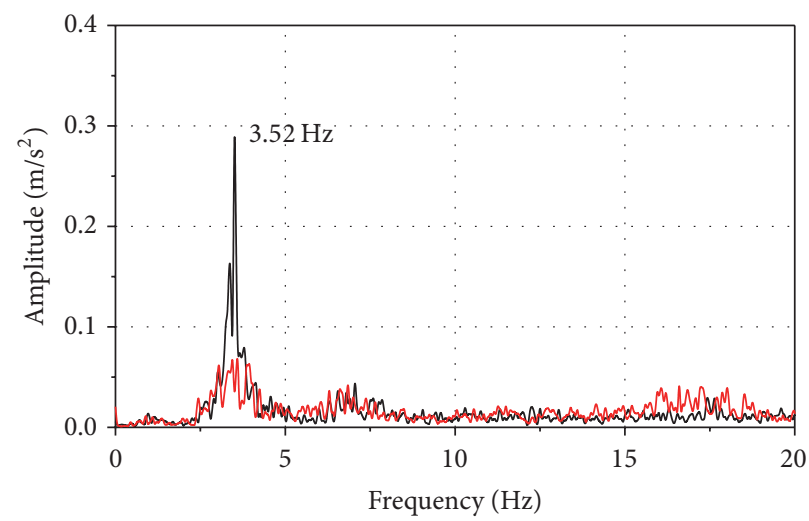

- Test 1

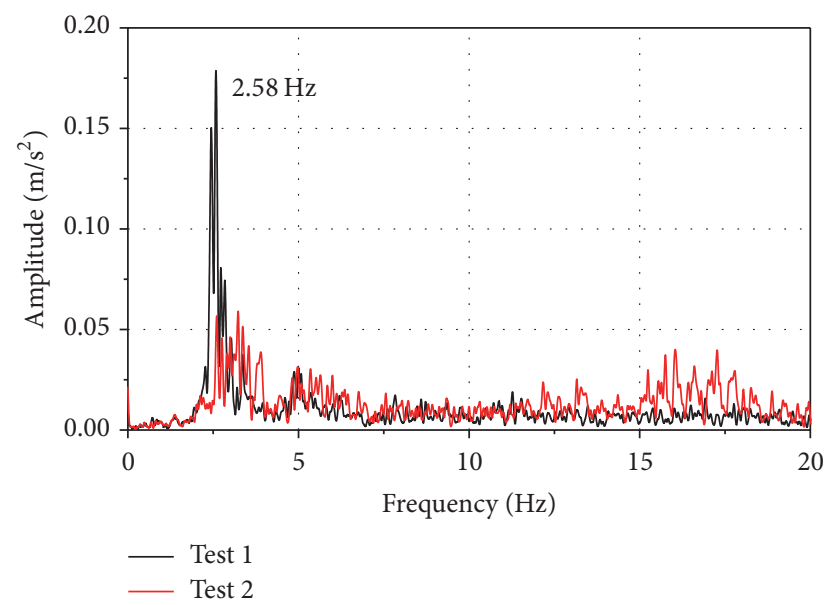

(b)

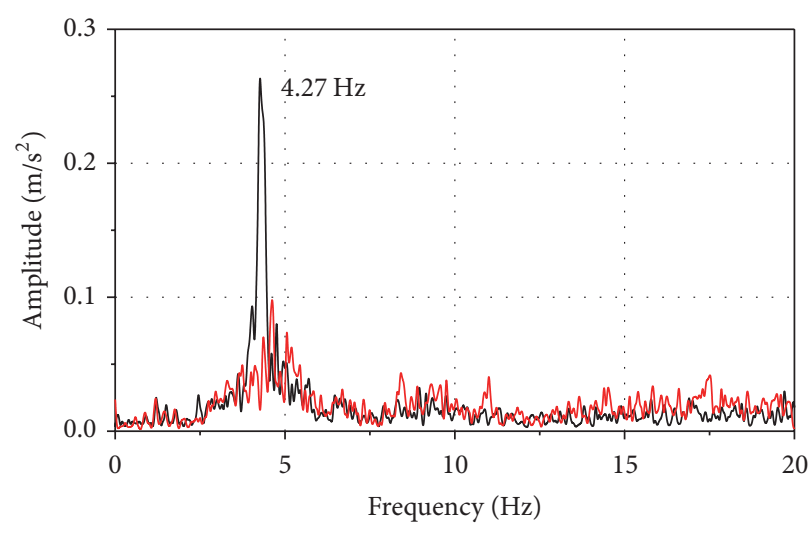

— Test 1

(c)

(d)

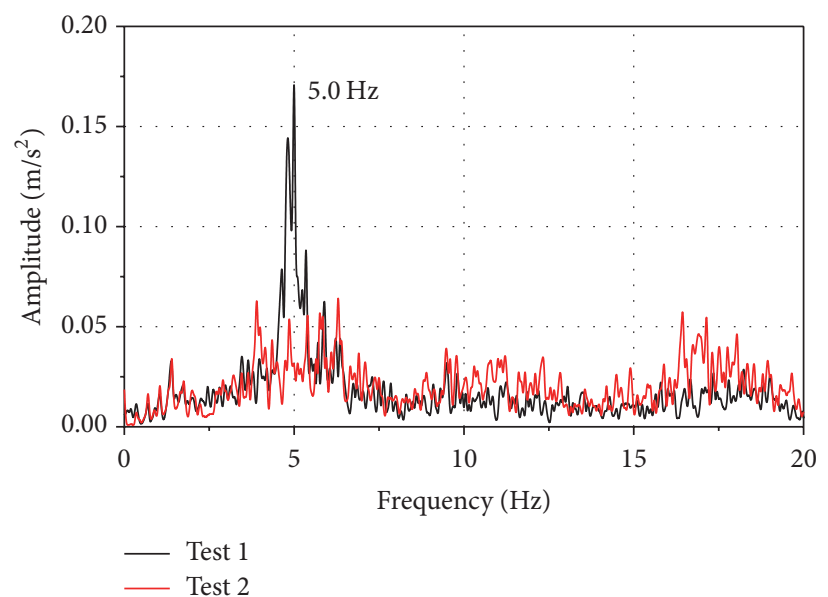

(e)

Figure 14: The comparison of frequency spectrum: (a) $10 \mathrm{~km} / \mathrm{h}$, (b) $15 \mathrm{~km} / \mathrm{h}$, (c) $20 \mathrm{~km} / \mathrm{h}$, (d) $25 \mathrm{~km} / \mathrm{h}$, and (e) $30 \mathrm{~km} / \mathrm{h}$.

the effects of the track flexibility into account in future work. Meanwhile, the curve passing performance of vehicle with wheel eccentricity should be investigated in future work.

\section{Conflicts of Interest}

The authors declare that they have no conflicts of interest. 


\section{Acknowledgments}

The authors wish to express their gratitude to State Key Laboratory of Traction Power for providing equipment and materials to this project and the China Sky Train Co., Ltd., for the cooperation and support. The authors are grateful for the financial support provided by the National Natural Science Key Foundation of China under Contract (Grant no. 51735012) and the Science and Technology Project of Sichuan Province (Grant no. 2017GZ0082).

\section{References}

[1] W. Zhai and C. Zhao, "Frontiers and challenges of sciences and technologies in modern railway engineering," Xinan Jiaotong Daxue Xuebao/Journal of Southwest Jiaotong University, vol. 51, no. 2, pp. 209-226, 2016.

[2] J. C. O. Nielsen and A. Johansson, "Out-of-round railway wheels-a literature survey," Proceedings of the Institution of Mechanical Engineers, Part F: Journal of Rail and Rapid Transit, vol. 214, no. 2, pp. 79-91, 2000.

[3] W. Zhai, Vehicle-Track Coupled Dynamics [M], Science Press, 4th edition, 2015.

[4] S. Iwnicki, Handbook of Railway Vehicle Dynamics [M], CRC Press, 2006.

[5] B. Morys, "Enlargement of out-of-round wheel profiles on high speed trains," Journal of Sound and Vibration, vol. 227, no. 5, pp. 965-978, 1999.

[6] K. Wang, W. Zhai, K. Lv, and Z. Chen, "Numerical investigation on wheel-rail dynamic vibration excited by rail spalling in high-speed railway," Shock and Vibration, vol. 2016, Article ID 9108780, 11 pages, 2016.

[7] K. Y. Wang, P. F. Liu, W. M. Zhai, C. Huang, Z. G. Chen, and J. M. Gao, "Wheel/rail dynamic interaction due to excitation of rail corrugation in high-speed railway," Science China Technological Sciences, vol. 58, no. 2, pp. 226-235, 2014.

[8] X. Jin, L. Wu, J. Fang, S. Zhong, and L. Ling, "An investigation into the mechanism of the polygonal wear of metro train wheels and its effect on the dynamic behaviour of a wheel/rail system," Vehicle System Dynamics, vol. 50, no. 12, pp. 1817-1834, 2012.

[9] G. Tao, L. Wang, Z. Wen, Q. Guan, and X. Jin, "Measurement and assessment of out-of-round electric locomotive wheels," Proceedings of the Institution of Mechanical Engineers, Part F: Journal of Rail and Rapid Transit.

[10] A. Johansson, "Out-of-round railway wheels-assessment of wheel tread irregularities in train traffic," Journal of Sound and Vibration, vol. 293, no. 3-5, pp. 795-806, 2006.

[11] A. Johansson and C. Andersson, "Out-of-round railway wheels-a study of wheel polygonalization through simulation of three-dimensional wheel-rail interaction and wear," Vehicle System Dynamics, vol. 43, no. 8, pp. 539-559, 2005.

[12] E. Brommundt, "A simple mechanism for the polygonalization of railway wheels by wear," Mechanics Research Communications, vol. 24, no. 4, pp. 435-442, 1997.

[13] J. Badger, S. Murphy, and G. Odonnell, "The effect of wheel eccentricity and run-out on grinding forces, waviness, wheel wear and chatter," The International Journal of Machine Tools and Manufacture, vol. 51, no. 10-11, pp. 766-774, 2011.

[14] X. Wu, M. Chi, and P. Wu, "Influence of polygonal wear of railway wheels on the wheel set axle stress," Vehicle System Dynamics, vol. 53, no. 11, pp. 1535-1554, 2015.
[15] D. W. Barke and W. K. Chiu, "A review of the effects of out-ofround wheels on track and vehicle components," Proceedings of the Institution of Mechanical Engineers, Part F: Journal of Rail and Rapid Transit, vol. 219, no. 3, pp. 151-175, 2005.

[16] K. L. Knothe and S. L. Grassie, "Modelling of railway track and vehicle/track interaction at high frequencies," Vehicle System Dynamics, vol. 22, no. 3-4, pp. 209-262, 1993.

[17] W. Zhai, H. Xia, C. Cai et al., "High-speed train-track-bridge dynamic interactions-part I: theoretical model and numerical simulation," International Journal of Rail Transportation, vol. 1, no. 1-2, pp. 3-24, 2013.

[18] W. Zhai, S. Wang, N. Zhang et al., "High-speed train-trackbridge dynamic interactions-part II: experimental validation and engineering application," International Journal of Rail Transportation, vol. 1, no. 1-2, pp. 25-41, 2013.

[19] R. Luo, J. Zeng, P.-B. Wu, and H.-Y. Dai, "Simulation and analysis of wheel out-of-roundness wear of high-speed train," Tiedao Xuebao/Journal of the China Railway Society, vol. 32, no. 5, pp. 30-35, 2010. 


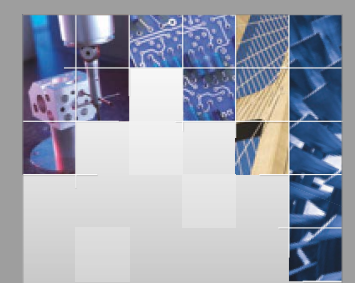

\section{Enfincering}
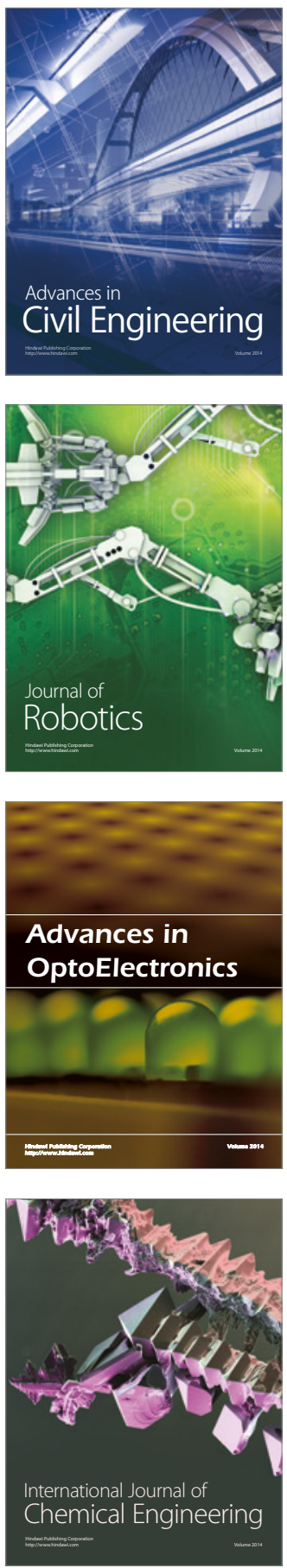

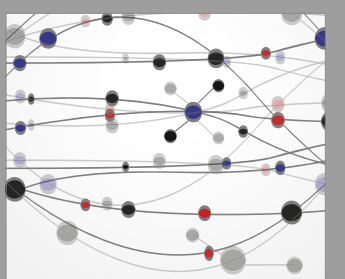

The Scientific World Journal

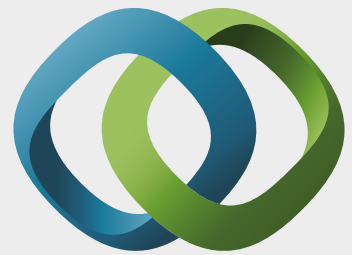

\section{Hindawi}

Submit your manuscripts at

https://www.hindawi.com
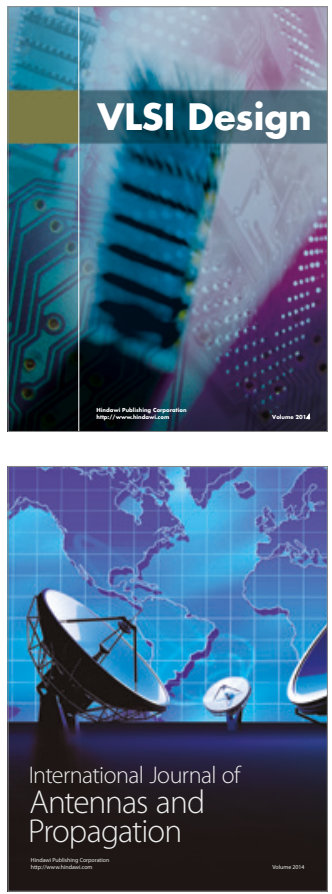

\section{Rotating}

Machinery
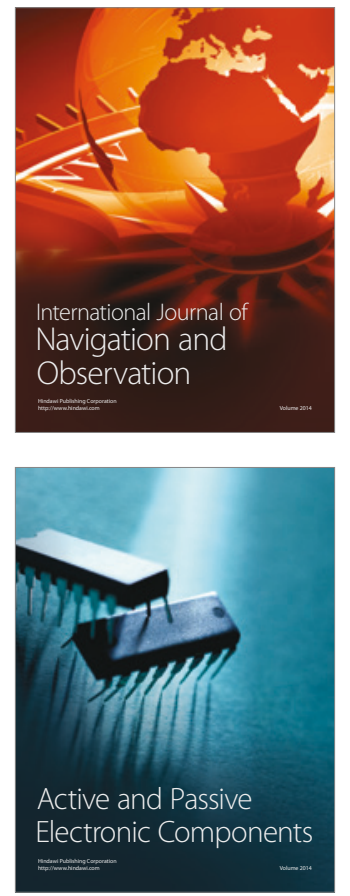
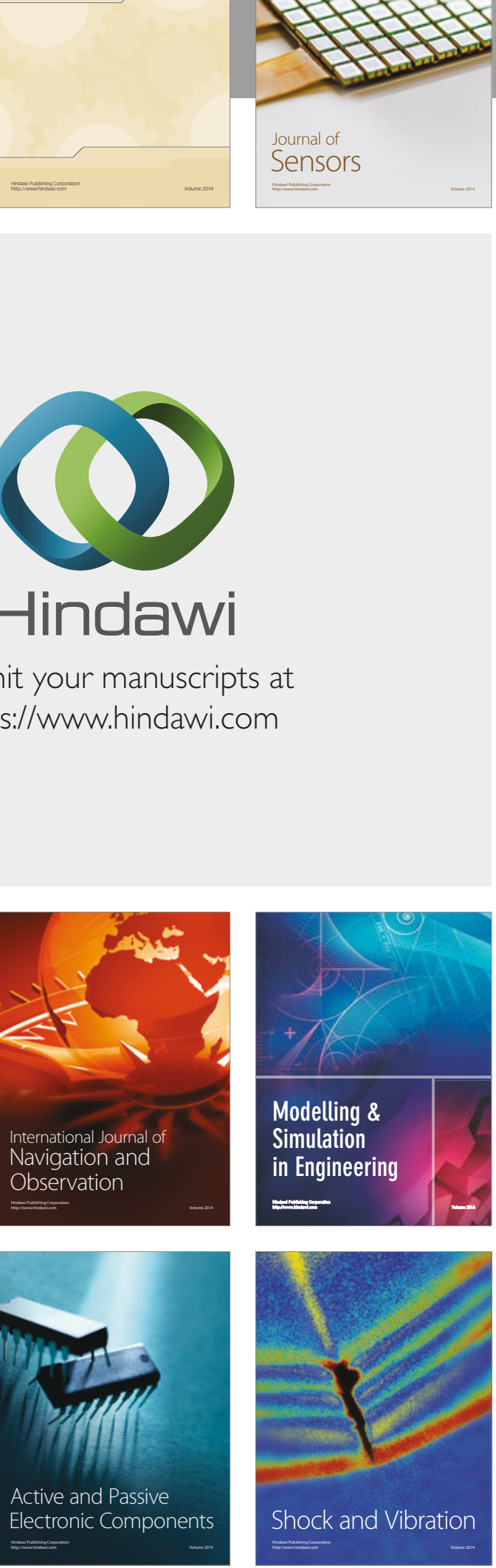
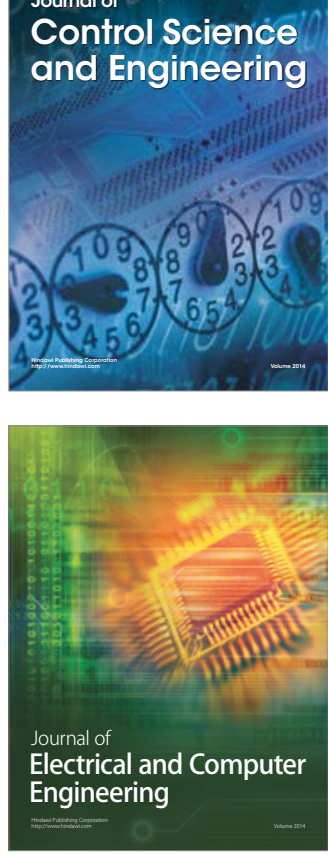

Distributed

Journal of

Control Science

and Engineering
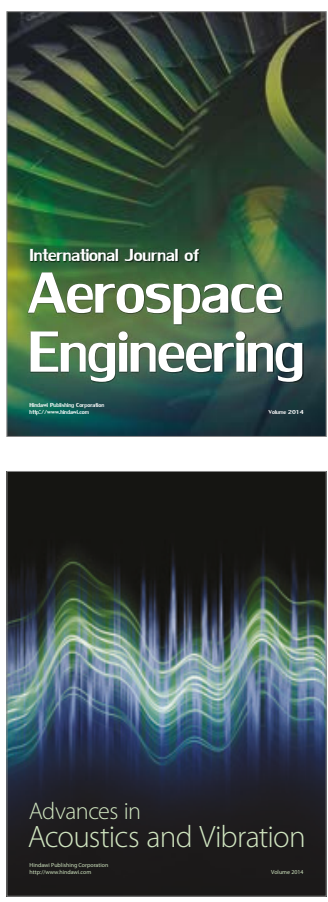

Sensor Networks 